\title{
Urdimento
}

Revista de Estudos em Artes Cênicas

E-ISSN: 2358.6958

\section{A espacialidade e a cena: reflexões a partir do projeto Na Selva das Cidades - Em Obras \#ocupasp}

Sara Fagundes Oliveira

\section{Para citar este artigo:}

OLIVEIRA, Sara Fagundes. A espacialidade e a cena: reflexões a partir do projeto $\mathrm{Na}$ Selva das Cidades Em Obras \#ocupasp. Urdimento, Florianópolis, v. 2, n. 38, ago./set. 2020.

DOI: http:/dx.doi.org/10.5965/14145731023820200022

Este artigo passou pelo Plagiarism Detection Software | iThenticate 
A espacialidade e a cena:

reflexões a partir do projeto Na Selva das Cidades - Em Obras \#ocupasp

Sara Fagundes Oliveira ${ }^{1}$

\begin{abstract}
Resumo
O presente artigo reflete, a partir do projeto desenvolvido pelo grupo teatral mundana companhia em Na Selva das Cidades - Em Obras \#ocupasp (2014-2017), sobre o espaço como um elemento estruturante da encenação. A partir disto, discute-se a potência crítica de práticas teatrais que entendem a espacialidade cênica para além de uma determinação estética - compreendendo-a como um espaço social -, o que permite ao teatro tecer críticas e descortinar questões que dizem da atual condição urbana de São Paulo.
\end{abstract}

Palavras-chave: Teatro. Espaço cênico. Espaço social. Cidade.

Spatiality and the stage:

reflections from the project Na Selva das Cidades - Em Obras \#ocupasp

\begin{abstract}
This paper present the space as a structuring element of staging, based on the project developed by the theater group mundana companhia in Na Selva das Cidades - Em Obras \#ocupasp (2014-2017). From this perspective arises the critical power of theatrical practices that understand scenic spatiality not only as an aesthetic determination, but as a social space. Thus, theater becomes a means of unveiling and criticizing issues that speak of the current urban condition of São Paulo.
\end{abstract}

Keywords: Theater. Scenic space. Social space. City.

Doutoranda em Artes Cênicas pela Universidade Federal do Estado do Rio de Janeiro (UNIRIO). Sara.fagundes@yahoo.com.br 
Há muito, pensar questões referentes à espacialidade da cena deixou de constituir uma análise a respeito de uma moldura, de um pano de fundo ou de um elemento figurativo da encenação, sobretudo se considerarmos as práticas teatrais atuais. Afinal, como aponta o pesquisador francês Patrice Pavis ao refletir sobre a cena contemporânea, "o espaço não é mais concebido como concha em cujo interior certos arranjos são permitidos [...], ele deixa de ser um problema de invólucro para tornar-se o lugar visível da fabricação e manifestação do sentido.” (Pavis, 2011, p.133).

No caso das práticas cênicas brasileiras contemporâneas, sobretudo aquelas desenvolvidas após o trabalho do grupo paulistano Teatro da Vertigem no início da década de 1990 - o conjunto de espetáculos denominado Trilogia Bíblica² que se consolidou como marco do teatro brasileiro recente -, observa-se uma emersão de espetáculos que se constroem em relação indissociável com a espacialidade da cena, sobretudo nos casos em que se desviam da caixa preta italiana e se encaminham para o território da cidade. Tais práticas, com um desejo político evidente, buscam muitas vezes discutir e refletir acerca das circunstâncias complexas e contraditórias da vida urbana, mas também procuram criar outras possibilidades de ser e estar no mundo hoje, por meio de uma pesquisa que perpassa de modo relevante pelo espaço. É dentro desse contexto que se inscreve o trabalho desenvolvido pelo grupo paulistano mundana companhia ${ }^{3}$ em Na Selva das Cidades (2014-2017).

O grupo 4 , fundado pelo atores-criadores Luah Guimarãez e Aury Porto, afirma-se desde o seu surgimento como propositor de um teatro crítico em

2 Os espetáculos Paraíso Perdido (1992), Livro de Jó (1995) e Apocalipse 1,11(2000) ocorreram respectivamente, em uma igreja, em um hospital e em um presídio e foram construídos dramatúrgica e cenicamente em relação direta com tais espacialidades. No que diz respeito ao deslocamento para outros espaços, Antônio Araújo, diretor do grupo, afirma que "[...] a pretensa neutralidade da 'caixa preta' do palco italiano não nos convinha. Necessitávamos para a fricção dos sentidos almejada um local de representação com força autônoma, que pudesse se colocar em pé de igualdade com o núcleo temático da peça”. (Araújo, 2011, p.166).

3 "Essa companhia de encontros conscientemente transitórios recebe o adjetivo antes do substantivo e tem seu nome integralmente grafado com letras minúsculas." (mundana companhia, Texto extraído do site do grupo. http://www.mundanacompanhia.com - Acesso em 28 dez. 2017)

4 A companhia encenou as seguintes peças: A Queda (2007), Das Cinzas (2009), o Idiota - uma novela teatral (2010), Tchekhov - uma experiência cênica (2010), Pais e Filhos (2012), O Duelo (2013), Na Selva das Cidades (2017), Dostoievski Trip (2017), Máquinas do Mundo (2018), Necropolítica (2018), MedeaMaterial (2019). 
relação às estruturas dominantes, tanto no campo artístico quanto político e social, e nesse sentido, uma prática que constantemente se questiona em suas próprias bases. Propondo a cada projeto a possibilidade de trabalhar com diferentes diretores, cenógrafos, atores, iluminadores e figurinistas, "a companhia teria [sempre] um novo corpo forjado na ideia de continuidade na transitoriedade" 5 . Em meio a este caminho de continuidades descontínuas, ao longo desses mais de dez anos de existência, a mundana desenvolveu uma parceria com a encenadora e iluminadora Cibele Forjaz, que dirigiu grandiosos projetos do grupo como O ldiota - uma novela teatral (2010) e Na Selva das Cidades (2017).

Tal encontro produziu trabalhos em que a espacialidade é determinante e fundante da cena, tirando-a de um plano de fundo, no que diz respeito ao seu status dentro do conjunto de elementos conformadores da encenação - que por muito se ligou a uma ideia de acessório, ornamento ou suporte. No caso da montagem do romance de Dostoievski, por exemplo, a companhia ocupou o Sesc Pompeia 6 e o espetáculo acontecia em um percurso pelo centro de cultura e lazer reformado por Lina Bardi. É na radicalização desse dispositivo espacial que caminha o trabalho desenvolvido em Na Selva das Cidades.

\section{Um texto tem muitas possibilidades}

O jovem Bertolt Brecht escreveu Na Selva das Cidades em meados da década de 1920 - a última versão do texto é de 1927 -, em Berlim, momento em que a Alemanha se reconfigurava política, social, econômica e culturalmente, após a destruição da Primeira Guerra Mundial. Enquanto isso, em Chicago - localização da peça -, vivia-se um momento de euforia com a modernidade em forma de ferro e vidro, autopistas e arranha-céus. É justamente em um símbolo do desenvolvimento e do progresso capitalista - a referida cidade norte americana que ocorre a luta entre as personagens C. Shlink, um comerciante de madeiras

5 mundana companhia. Texto extraído do site do grupo. http://www.mundanacompanhia.com. Acesso em: 28 dez. 2017

${ }^{6}$ Especificamente sobre a temporada em São Paulo. O espetáculo circulou por diversos festivais e cidades pelo país, sempre em espaços alternativos. 
malaio e George Garga, funcionário de um sebo de livros que se mudou, junto com sua família, do campo para a cidade grande. O texto é dividido em onze cenas independentes que acontecem como se fossem rounds de uma luta de boxe. A cada sequência um confronto vai traçando o caminho da família e dos personagens rumo à decadência na selva das cidades. Embates muitas vezes contraditórios, sem uma explicação clara.

Prólogo:

Os senhores encontram-se no ano de 1912 na cidade de Chicago. Observam a inexplicável luta entre dois homens e acompanham a decadência de uma família que veio do campo para a selva da cidade grande. Não quebrem a cabeça sobre os motivos dessa luta, mas participem das jogadas humanas, julguem imparcialmente o método de luta dos adversários e voltem o seu interesse para o final. (Brecht, 2016, p.29).

O texto de Brecht aborda a condição humana diante das transformações radicais que acontecem no que o sociólogo e filósofo Henri Lefebvre (2001 [1968]) considera como a passagem da "cidade como obra" para a "cidade como produto", com a consolidação do modo de produção capitalista, e como o homem se relaciona com novas condições da vida urbana que emergem com força naqueles tempos. Na perspectiva de Fernando Peixoto (1974, p. 52-53),

\begin{abstract}
Brecht escreve um drama que põe a nu um dos aspectos fundamentais e mais cruéis da civilização capitalista: o isolamento do indivíduo, sua redução a instintos primitivos e bestiais, "uma luta pela vida" que só se encontra assim no mundo animal. [...]. Os homens se entredevoram para sobreviver. O capitalismo institucionaliza a luta cotidiana, onde todos os golpes são justificáveis. A cidade grande é uma selva onde triunfa o mais forte e os que vêm do campo (como Brecht, de Augsburg para Berlim) são massacrados se não aceitam os termos e as armas propostos pelos inimigos, pela própria violência da cidade.
\end{abstract}

Como se observa pela fala de Peixoto, a questão do ambiente sobre o qual "os homens se entredevoram", a selva das cidades - ou seja, o espaço -, aparece como um elemento real, concreto, que, ao ser aderido à ficcionalidade da peça, passa a estruturar sua dramaturgia; mais do que isso, aparece também como um 
dispositivo épico ${ }^{7}$ que evidencia a realidade social vivida naquele momento específico, desvelando questões referentes ao homem e ao espaço submetidos então à lógica e à dinâmica capitalista. O espaço real da vida ressoa e reverbera no espaço ficcional da peça. A mundana companhia transpôs essas questões para os dias atuais por meio de deslocamentos pela cidade, procurando em cada um dos distintos lugares por onde passou, leituras sobre o homem nas selvas urbanas aqui e agora.

Para os eventos teatrais que fogem aos padrões espaciais tradicionais e se constroem em relação direta e indissociável com os lugares ocupados, Kathlenn Irwin (2008) se utiliza do termo site-specific. A autora se apoia na premissa - indo contra a ideia de que a espacialidade cênica é um vazio quando não está preenchida pelo espetáculo -, de que o espaço não é um elemento inerte e passivo e que "todo espaço está carregado de uma multiplicidade de significados e histórias"8 (Irwin, 2008, p.155). Desse modo, as práticas site-specific privilegiam muitas vezes "o lugar [seus significados e histórias] em relação a elementos mais tradicionais da performance, como ator e texto"9 (Irwin, 2008, p.158). Cibele Forjaz (2019), ao pensar sobre este trabalho da companhia aponta que o projeto pode ser lido como um site-specific ampliado, pois é

multiplicado por mil. Não é que esta peça é para uma Igreja e é na Igreja que vai ser. Não. Essa peça ela é as mil caras da cidade, os milhões de buracos e das sujeiras de uma cidade. [...] o site-specific é a cidade, então ele precisaria de mil versões. E a cada lugar, um site-specific e uma concepção pra aquele lugar. (Forjaz, 2019).

Cabe dizer, que a fala de Forjaz indica uma compreensão da cidade como organismo vivo e múltiplo que não pode ser lido - e nem evocado - como uma

7 O texto Na Selva das Cidades - terceira peça do dramaturgo - é considerada por muitos autores como uma dramaturgia ainda com traços expressionistas e foi escrita antes das suas formulações para o teatro épico. No entanto, ainda que Brecht não tivesse formulado tais proposições, elas já começavam a emergir, sobretudo no aspecto dramatúrgico. Fernando Peixoto, sobre o texto, aponta que "o conteúdo é dramático, mas apresentado de forma épica. Nesse sentido, Na Selva das Cidades, por sua estrutura, pelo radicalismo de sua proposta e pelo vigor de sua linguagem, antecipa o teatro épico, a narração no palco." (Peixoto, 1974, p.53).

8 Every space is charged with a multiplicity of meanings and histories. (Tradução nossa)

9 Characteristically, in situ performances privilege place over more traditional performance elements such as actor and text. (Tradução nossa) 
totalidade homogênea. Afinal, "as mil caras" às quais a diretora se refere, dizem justamente das muitas cidades - e realidades - que coexistem em São Paulo. Nesse sentido, o grupo propõe um trabalho que se estrutura a partir das instabilidades e das distintas identidades do território urbano. Não à toa, o projeto adquiriu proporções imensas na procura pelos tantos "buracos e sujeiras" da urbe.

À respeito dessas práticas em que o espaço passa a elemento estruturante da encenação, para o encenador e professor André Carreira, uma cena que se constrói a partir de determinada realidade urbana não poderia inscrever a cidade apenas como cenografia, pois o evento teatral é sempre redefinido "pelos usos sociais e culturais predominantes, e aquilo que poderia ficar atrás da cena como elemento cenográfico sempre ocupará interstícios da dramaturgia porque é um dispositivo vivo por onde circulam pessoas em seu cotidiano" (Carreira, 2009, p.4). Nesse sentido, aponta o potencial dramatúrgico que a silhueta urbana e seus fluxos configuram:

A cidade é dramaturgia porque é produtora de sentidos, e sempre interfere no espetáculo condicionando seu funcionamento e estabelecendo condições de recepção e mesmo promovendo a produção dos signos na cena. Essa escritura é realizada pela ação imagética da arquitetura - pela presença do aparato urbano construído -, pelas ações e atitudes dos sujeitos que ocupam os espaços da cidade, e pela força dos discursos institucionais que tratam sempre de dominar a construção da paisagem urbana. (Carreira, 2009, p.4).

Carreira afirma ainda que tais práticas funcionam necessariamente como uma ruptura nos fluxos do espaço urbano, reorganizando a experiência cotidiana, uma vez que se apropriam de lugares que não foram organizados para as práticas cênicas. E é justamente por essa ruptura, que o evento teatral se politiza.

No caso da mundana companhia, o processo de trabalho do grupo com o texto de Brecht teve início em 2014 e se desenvolveu, substancialmente, em dois momentos: (i) Na Selva das Cidades - Entre Tempos e Espaços e (ii) Na Selva das Cidades - Em Obras. A primeira etapa, realizada ao longo dos anos de 2014 e 2015², consistiu na busca pelo encontro da dramaturgia com a atual realidade de São

10 Etapa que se propunha como uma pesquisa ainda sem vistas à montagem da peça. 
Paulo. Essa etapa se construiu a partir de imersões em espaços pungentes da cidade, experimentando as ações evocadas pelo texto e criando, a partir da ocupação desses espaços, as estruturas e a espessura das cenas. A cada local encontrado pelo grupo, um quadro específico da peça era trabalhado, ou seja, em cada um dos lugares por onde passava, ia-se tecendo a relação do texto e da cena com as múltiplas realidades que coexistem em São Paulo.

Entretanto, o desejo de encenar Na Selva das Cidades para além das experiências de caráter mais aberto surgiu e ao retomar à sala de ensaios e a uma possível relação tradicional com o espaço, texto e espectadores, a companhia precisou pensar uma forma que não sintetizasse em um único espetáculo as experiências realizadas; mas, um modelo que se testasse no esgarçamento de sua própria forma, nas idas e vindas, nas construções e desconstruções realizadas a partir das incursões pelo espaço urbano. De acordo com Forjaz (2016, p. 17):

Voltar ao centro da cidade, à sala de ensaio, ao texto e, em última instância, ao teatro, parecia não fazer mais sentido. As experiências que vivemos na cidade eram tão mais potentes, radicais e, principalmente, mais vivas e urgentes, do que simplesmente montar mais uma peça de teatro. [...]. Resolvemos, juntos, abrir radicalmente o espetáculo para a potência das experiências vividas na cidade. A cada nova ocupação, faríamos uma nova pesquisa de campo e uma ocupação singular onde tudo se transforma na relação com o espaço ocupado, as pessoas que frequentam e a sua história.

A segunda etapa do trabalho, Na Selva das Cidades - Em Obras, compreendeu 15 ocupações ${ }^{11}$, ao longo de dois anos - 2016 e 2017 - também na cidade de São Paulo. Esta etapa sofreu uma subdivisão, que separaram as três primeiras ocupações, das 12 subsequentes. As Ocupações \#1, \#2 e \#3, aconteceram em espaços dos SESCs da cidade e em um centro cultural, e as

11 Encenações em tempos e espaços específicos. Em cada ocupação era apresentada uma montagem diferente da peça: Ocupação \#1 - Sesc Ipiranga - SP (2015); Ocupação \#2 - Instituto Capobianco - São Paulo (2015); Ocupação \#3 - Sesc Pompéia - São Paulo (2016).; Ocupação \#4 - Pessoal do Faroeste (Sede da Companhia do Faroeste, Região da Luz), Ocupação \#5 - Águas (Yacht Club de Santo Amaro), Ocupação \#6 - Terras (Vila Coliseu, Vila Olímpia), Ocupação \#7 - Comida (Sindicato dos Carregadores da CEAGESP, Vila Leopoldina), Ocupação \#8 - Reciclagem (Favela do Escorpião, Jardim Ipanema), Ocupação \#9 - Pele (Madeireira Amarante, Butantã) Ocupação \#10 - Love Story (Centro), Ocupação \#11 - Morte (Cemitério da Lapa), Ocupação \#12 - Espetáculo (Paróquia Divino Espírito Santo, Arthur Alvim), Ocupação \#13 - Matas (Horto Florestal), Ocupação \#14 - Catch (Viaduto Alcântara Machado, Região da Luz), Ocupação \#15 - Caos (Teatro Oficina Uzyna Uzona). 
seguintes, da \#4 a \#15, fizeram parte de um subprojeto, o Na Selvas das Cidades - Em obras - \#ocupasp. Nesse desdobramento, o grupo retornou aos espaços nos quais imergiram durante a primeira fase do projeto, colocando a encenação já estruturada para ser atravessada e reconstruída a partir da realidade dos lugares ocupados. Forjaz, pensando no espaço urbano como elemento estruturante do projeto, aponta que "a concepção que a gente conseguiu ter na Selva, a partir da experiência forte das imersões, foi que era impossível ter uma [única concepção]. Que qualquer uma e qualquer teatro diminuiria. Porque já que a personagem principal é a cidade, o lugar é o diretor" (Forjaz, 2019).

\section{A produção capitalista do espaço urbano}

No que diz respeito a uma discussão específica sobre o espaço, para Henri Lefebvre, não há como pensar e refletir sobre uma sociedade que não se realize em uma determinada espacialidade. Não há uma sociedade a-espacial, e não existem processos sociais que não ocorram no e pelo espaço. Portanto, não existimos sem a produção de espacialidades. "O espaço (social) é um produto (social)" (Lefebvre, 1991, p.26)12 afirma o autor. Ou seja, o espaço não pode ser considerado como um meio inócuo ou como uma categoria apriorística, mas deve ser pensado a partir das relações sociais, como um produto - em princípio não mercantilizado. Não pode ser reduzido a um objeto, mas "resulta de uma sequência e de um conjunto de operações" (Lefebvre, 1991, p.73) (13 $^{13}$ que se relacionam dialeticamente. Ao mesmo tempo que produto o espaço é também produtor - é condição e resultado.

Sendo causa, efeito e razão das práticas sociais, Lefebvre argumenta que cada sociedade produz seu espaço. Desse modo, a sociedade capitalista que se estabelece no século XX produziu um "espaço abstrato que contém o mundo da mercadoria" (Lefebvre, 1991, p.53) ${ }^{14}$. Assim, aponta que a hegemonia desse modo

12 (Social) space is a (social) product. (Tradução: Doralice Barros Pereira e Sérgio Martins)

13 It is the outcome of a sequence and set of operations and thus cannot be-reduced to the rank of a simple object. (Tradução: Doralice Barros Pereira e Sérgio Martins)

14 Capitalism and neocapitalism have produced abstract space, which includes the 'world of commodities' 
de produção se exerce por meio de configurações espaciais. Ou seja, os arranjos espaciais reverberam e são reverberações da dinâmica perversa e opressiva do capital. No entanto, o autor pondera que embora o exercício do poder, do controle e da violência se realizem por meio do espaço, é também nele que se encontram as possíveis resistências à opressão exercida pelo sistema:

[...] o espaço abstrato, aquele da burguesia e do capitalismo, enquanto ligado à troca (de bens e mercadorias, de palavras, escritas e faladas etc.) mais que qualquer outro, implica consensos. É preciso acrescentar que nesse espaço a violência não fica sempre latente e oculta? É uma de suas contradições: entre a segurança aparente e a violência que ameaça sem cessar explodir e, às vezes, aqui ou ali, explode. (Lefebvre, 1991, p. 57). ${ }^{15}$

Pensando especificamente sobre a cidade, Lefebvre defende que os processos de industrialização que acontecem a partir do século XIX refletem no tecido urbano por meio dos projetos modernistas do século XX, convertendo a cidade de obra em produto. De "centros de vida social e política onde se acumulam não apenas as riquezas como os conhecimentos, as técnicas e as obras (obras de arte, monumentos)" (Lefebvre, 2001, p.12), ou seja, de valor de uso, o espaço urbano, "na orientação irreversível em direção ao dinheiro" (Lefebvre, 2001, p.12), converte-se em valor de troca, em mercadoria a ser consumida. Contexto que diz da Chicago imaginada por Brecht em meados de 1920, mas que diz também da nossa realidade aqui e agora, cem anos depois. Entretanto, o teórico afirma que "O uso principal da cidade, isto é, das ruas e praças, dos edifícios e dos monumentos, [ainda] é a Festa (que consome improdutivamente, sem nenhuma outra vantagem além do prazer e do prestígio, enormes riquezas em objetos e em dinheiro)" (Lefebvre, 2001, p.12). A cidade é, acima de tudo, o lugar da contradição.

No caso de São Paulo, a geógrafa Ana Fani Carlos, apoiada no pensamento de Lefebvre, aponta o paradoxo em que consiste a cidade hoje: autora afirma-a

[...]. (Tradução: Doralice Barros Pereira e Sérgio Martins)

15 Abstract space, the space of the bourgeoisie and of capitalism, bound up as it is with exchange (of goods and commodities, as of written and spoken words, etc.) depends on consensus more than any space before it. It hardly seems necessary to add that within this space violence does not always remain latent or hidden. One of its contradictions is that between the appearance of security and the constant threat, and indeed the occasional eruption, of violence. (Tradução: Doralice Barros Pereira e Sérgio Martins) 
como "o campo de consolidação da racionalidade fundada na reprodução sempre ampliada do capital, sob comando do Estado" (Carlos, 2004, p. 225), ao mesmo tempo e de modo contraditório que a entende como o "lugar da realização da vida humana em todas as suas dimensões" (Carlos, 2004, p. 225). É justamente nessa oposição que localizamos de modo bastante evidente o estudo de caso a ser brevemente desenvolvido a seguir. Afinal, as espacialidades ocupadas pela mundana companhia ao longo do projeto revelam esse fenômeno dialético que constitui a produção do espaço: ao mesmo tempo que são lugares constantemente violentados pela dinâmica capitalista, são pontos de resistência coletiva que lutam para subverter a lógica da cidade como valor de troca, para a cidade como valor de uso.

\section{Em Obras: Ocupação \#6 - Terras}

O encontro da companhia com a comunidade Coliseu ${ }^{16}$ ocorreu em 2014 durante as pesquisas imersivas realizadas pelo projeto Na Selva das Cidades Entre tempos e Espaços. O grupo, que investigava a espacialidade da Avenida Luís Carlos Berrini e o novo centro econômico da capital - e elegeu o Shopping JK para a leitura do segundo quadro da peça -, descobriu a pequena favela em uma deambulação pelas ruas do entorno do centro de lazer e compras. Nessa fase do projeto, realizaram na casa de Dona Terezinha, uma moradora da comunidade, a leitura do quadro três ${ }^{17}$. Com prosseguimento do trabalho e seu desdobramento com o Na Selva da Cidades - Em Obras -\#ocupasp, o grupo decidiu retornar à favela para a realização de uma versão integral da peça específica para aquela localidade.

Ao chegar à entrada da Rua Coliseu, que faz esquina com a suntuosa Rua Funchal no bairro Vila Olímpia, as contradições parecem dar as boas-vindas. Espremida entre arranha-céus de vidro espelhado e o Shopping JK - conhecido

${ }^{16}$ A Favela Coliseu existe desde meados de 1960, quando as primeiras famílias de imigrantes pernambucanos e mineiros, em busca de oportunidade de trabalho na selva da cidade grande, instalaram-se na área que na época era uma região pouco ocupada, uma área alagadiça sem infraestrutura urbana.

${ }^{17}$ Que tem como indicação da rubrica a casa da família Garga. 
por ser o mais luxuoso da cidade -, a favela, em sua entrada, possui uma base móvel da Polícia Militar que parece definir e garantir a separação entre os dois mundos. Com sua arquitetura de tijolos a vista, madeirites e papelões, a comunidade tenta resistir aos algozes da especulação imobiliária, abrigando cerca de 270 famílias há mais de 50 anos. No entanto, a área faz parte de um programa maior - Operação Urbana Consorciada Faria Lima18 -, de "requalificação" de três comunidades da região, afinal a presença das favelas, aos olhos do capital, perturba a imagem da área mais rica da cidade, conhecida como a "manhattan brasileira”. Alguns barracos, naquele momento - fevereiro de 2017 -, já estavam sendo demolidos para a construção de prédios residenciais, a princípio e em tese, destinados aos moradores da Coliseu. No entanto, o momento vivido pela comunidade é de completa incerteza, pois primeiro os moradores precisam desocupar suas casas para, em um futuro nebuloso - e esse futuro implica justamente no fato de terem condições de comprar um imóvel -, voltarem para se abrigar nos edifícios homogêneos e pasteurizados que caracterizam grande parte dos projetos de habitação social do país.

A companhia tinha como ponto de partida perpassar toda a peça - do prólogo ao quadro onze - respeitando o texto e as situações evocadas por ele, mas, ao mesmo tempo, desejava que a encenação fosse contaminada pela vida que vibra na Coliseu. O espetáculo aconteceria em um percurso pela comunidade e a intenção era relacionar cada quadro da dramaturgia - e seus conflitos essenciais - a um lugar específico da favela. A espacialização das cenas ocorreria, portanto, de acordo com as características dos lugares encontrados.

O mês era fevereiro e a cidade estava às vésperas do carnaval. O espetáculo teve início com um cortejo que entoava marchinhas carnavalescas e misturava atores, atrizes, equipe técnica e membros da comunidade - sobretudo crianças -

18 Operação Urbana é um instrumento urbanístico - introduzido pelo Estatuto da Cidade - utilizado na requalificação de áreas urbanas por meio de uma parceria público-privada. Um instrumento que, na prática, revela-se como ferramenta perversa de reprodução do modo de produção capitalista das cidades. No caso da OPFV, em um primeiro momento - até meados da década de 1990 -, a Coliseu e mais duas comunidades seriam removidas da área e seus moradores transferidos para um conjunto habitacional em outro local. Entretanto, após anos de luta e organização coletiva dos moradores da Coliseu atualmente vigora um projeto de construção de habitações de interesse social destinada à compra pela população da comunidade. 
, que juntos, convidaram o público para o acontecimento. Rosana - líder da comunidade - à frente do "bloco" chamava a todos: "vamos comunidade, o teatro tá começando!". Atores, moradores e público ${ }^{19}$ caminharam em grupo, cantando e dançando, do Bar da Regina - ponto de encontro do início da peça que se localiza no começo da Rua Coliseu próximo à esquina com a Rua Funchal - até a sede da comunidade.

Dentro do espaço coberto da sede havia alguns engradados destinados ao assento da plateia, dispostos na forma de um quadrado. Na parede do fundo liase "Sou Coliseu" pintado com cores $\operatorname{coloridas}^{20}$. O prólogo foi realizado por uma moradora da comunidade, que, dentro do espaço delimitado pelo público, através de um microfone, lia o texto em um caderno. Uma batida no gongo, uma mudança sutil na luz - ainda era dia e as luzes naturais invadiam o espaço - e George Garga ${ }^{21}$ anunciou a rubrica do texto. E foi ali, dentro do sebo de livros C. Maynes / Sede da Coliseu que teve início o confronto entre os dois homens.

Para o segundo quadro da peça o público foi conduzido para um terreno repleto de entulhos de construção, com alguns barracos em processo de demolição. Rodeados por muros imensos, que deixavam ver os edifícios espelhados do entorno, a tensão visual entre as duas realidades era muito evidente e intensa, sobretudo porque ainda era dia e os elementos do terreno e do entorno se faziam muito presentes. As ações realizadas pelos atores - que não Shlink e Garga -, caracterizados como operários de obras, com capacetes, luvas e óculos de proteção, giravam em torno do manejo dos entulhos da (des) construção. A luz verde de um refletor instalado em um dos muros, associado à música eletrônica - que vinha de uma caixa de som móvel em cima de um carrinho que percorreu toda a peça - potencializavam a atmosfera de uma grande máquina em funcionamento - o escritório do comerciante, nesse caso, um canteiro de obras destruído. Enquanto os outros atores trabalhavam com os entulhos e os dois

\footnotetext{
19 Importante ressaltar que o público da Ocupação \#6 - Terras em sua maioria era composto por moradores da favela. Havia poucas pessoas vindas de fora da comunidade.

20 O referido grafite já existia na Sede. Não foi uma intervenção da companhia.

21 Interpretado pelo ator Lee Taylor.
} 
personagens principais travavam o diálogo que revela o aceite da luta por Garga ${ }^{22}$, foram incluídas não apenas referências espaciais do local, mas também da situação vivida pelos moradores - a iminência de remoção e a construção dos prédios -, de modo que para além do âmbito espacial, a realidade da favela passava a fazer textualmente parte da peça. No momento em que Shlink passa seus bens para Garga, por exemplo, e diz, "Esse terreno todo é seu. Esse negócio de madeiras e de construção civil também é seu." ${ }^{23}$, ou ainda quando Garga indaga "O senhor se referia a todo terreno, Mr. Shlink? A todo o estabelecimento, os barracos, o inventário?"24. Naquela espacialidade, o confronto entre o poderoso Shlink e o humilde funcionário do sebo de livros se traduzia de forma muito potente na opressão vivida pela comunidade em oposição aos edifícios do entorno - que materializam justamente o poder opressivo e perverso do dinheiro. Como diz o comerciante, e que parece ter sido formulado em relação àquela realidade sócioespacial, "Minha casa e o meu negócio, por exemplo, me colocam em condições de tocar os cachorros no seu encalço. Dinheiro é tudo." (Brecht, 2016, p.72).

Avançando no tempo e no espaço, o espetáculo passou pela casa da moradora mais antiga da comunidade, no quadro três, pelo Bar da Dona Regina, no qual aconteceram os quadros quatro e cinco - situados pela rubrica no Hotel Chinês - e o quadro seis, que tem com indicação do texto a Mata do lago Michigan foi realizado na entrada da comunidade na Rua Coliseu. Para o quadro sete o público foi conduzido, ao som de um samba antigo, à porta de uma das igrejas evangélicas da rua. A mãe do noivo anunciou o casamento de Jane Larry ${ }^{25}$ e George e de dentro da igreja saiu o pastor Danilo cantando uma canção gospel. Depois

22 Importante pontuar que no primeiro quadro, Shlink inicia o confronto com Garga tentando comprar sua opinião sobre um livro, ainda que o malaio não se interesse pelos escritos, apenas pelo fato de poder comprar a opinião do rapaz. O jovem funcionário se recusa a vendê-la, mesmo com a pressão exercida por Shlink e seu bando, mesmo com sua demissão do sebo. No segundo quadro Garga procura Shlink para aceitar a luta.

23 O texto original: "Essa casa e esse negócio de madeira, registrados no cadastro público de bens e imóveis da cidade de Chicago com o nome Shlink, no dia de hoje passam para o senhor George Garga de Chicago". (Brecht, 2016, p. 73).

${ }^{24}$ O texto original: "O senhor se referia ao seu negócio de madeiras, o legítimo Shlink? O estabelecimento, os troncos, o inventário?”. (Brecht, 2016, p. 73).

25 Namorada de Geoge Garga interpretada pela atriz Nana Yasbek. 
saíram os noivos que foram recebidos com chuva de arroz pela plateia ${ }^{26}$. Após a música o público foi convidado para o coquetel de núpcias no Bar da Dona Graça, que ficava na edificação vizinha. Ao chegar no bar, as fitas de led que atravessavam a rua demarcavam o ambiente festivo. O estabelecimento em madeira possuía uma pequena varanda onde estavam alguns de seus frequentadores e, da rua, o público assistia frontalmente a cena. Garga distribuiu pizza aos convidados e comentou sobre as melhoras trazidas pelo comerciante de madeira à vida da família, desde que ele passou a sustentá-los ${ }^{27}$. Vestes novas, móveis novos, anunciava a orgulhosa Mãe ${ }^{28}$ no início do quadro. Embora a localização dada pelo texto seja a casa renovada pelo mobiliário, a tradução na fartura do banquete trazia a dimensão da ascensão econômica da família. Àquela altura da peça, as crianças estavam completamente envolvidas na cena, fosse por Jane que carregava uma delas no colo, ou pelo fato de um posicionamento claro diante da luta entre os dois homens. Na chegada do malaio à festa, as crianças entoaram um grito em coro: "ih, fora!", e ao longo da cena, acompanhados também pelos adultos, repetiram o gesto em vários momentos. O comerciante aparece na celebração para comunicar a Garga que recebeu uma carta do tribunal da Virgínia, na qual é acusado pela venda dupla da madeira ${ }^{29}$. Shlink pressiona para que ele vá para a cadeia em seu lugar, afinal é o mais jovem. George acaba aceitando. Sua família, que parecia se estar se reintegrando na celebração do matrimônio retoma o processo de ruína. Ele se entrega à polícia, Jane retorna ao Hotel Chinês para trabalhar como profissional do sexo e a Mãe desaparece.

Saltando em direção ao final do espetáculo, o quadro dez encaminhou o público para a batalha final entre os dois homens, no "acampamento abandonado dos trabalhadores na estrada de ferro" (Brecht, 2016, p.264) -, novamente, no

${ }^{26}$ Importante pontuar que a cena do casamento na igreja não existe no texto. O que existe é a festa na casa da família - renovada pelo mobiliário - para celebrar a união do jovem casal.

27 Situação revelada no quadro três: Garga em posse do dinheiro de Shlink abandona a família. Shlink, por sua vez, pede abrigo na casa dos Garga e promete sustentá-los, agora que o principal esteio da família está desaparecido. A família, mesmo que sob a desconfiança da mãe, aceita a proposta.

28 Interpretada pela atriz Sylvia Prado.

${ }^{29}$ Golpe cometido por Garga ao receber de Shlink sua madeireira, no quadro 2. 
terreno com entulhos do segundo quadro. No entanto, já era noite e entorno ficava menos visível. A iluminação branca indireta, vinda de um refletor tipo panelão, evidenciava os escombros do terreno e a vegetação que crescia sobre os muros. O confronto final entre Shlink e Garga marca alguns pontos do combate que fora travado entre eles. Em um diálogo que por vezes se acalorava, os dois trocaram os últimos golpes, por vezes verbais, por outras, físicos. Shlink só queria a luta e Garga o seu fim. Independente disso, George, em cima de uma pilha de escombros, após arrancar brutalmente os sapatos do malaio, grita aos quatro cantos: "o mais jovem vence a luta" (Brecht, 2016, p.265). A plateia aplaudiu, assobiou e comemorou. Após Garga abandonar Shlink e deixar a cena, aparecem os linchadores - atores com roupas pretas e lanternas de cabeça - que adentram o terreno com sinalizadores de fumaça vermelha na mão, ao som pulsante dos tambores. Eles cercam o comerciante, a tensão aumenta. Maior intensidade dos tambores e Shlink é linchado. Blackout. Fogos de artifício explodem.

O quadro onze foi anunciado ainda dentro do terreno por um dos atores ${ }^{30}$ com vestes sociais, um capacete de obras e uma placa de venda de imóveis. Ele veio comunicar o pedido de reintegração de posse da área, exigindo que as famílias se retirassem do local. O público resistiu, mas foi empurrado para fora e se posicionou na entrada do terreno, na qual barracos em demolição foram iluminados. Uma fita de obras indicando a interdição do local também foi inserida. A cena, que corresponde à venda da madeireira de Garga, de sua irmã e de seu pai para Pat Mankey, converteu-se na venda da comunidade para uma grande empreiteira. George debateu o valor com Mankey, que se interessava em comprar o espaço. A plateia interferiu diretamente na cena reivindicando valores mais elevados, questionando que o valor oferecido - dez mil reais - não comprava sequer um barraco. Pat, por fim, ofereceu cinquenta milhões e um apartamento para cada família. Garga perguntou ao público se deveria vender. A favela aceitou a oferta. Estava feito o negócio. Terreno vendido, Garga parte para Nova York, fim do espetáculo.

30 Interpretado pelo ator Mariano Mattos Martins. 
Figura 1 - Ocupação \#6 - Terras - Quadro um - Sede Sou Coliseu

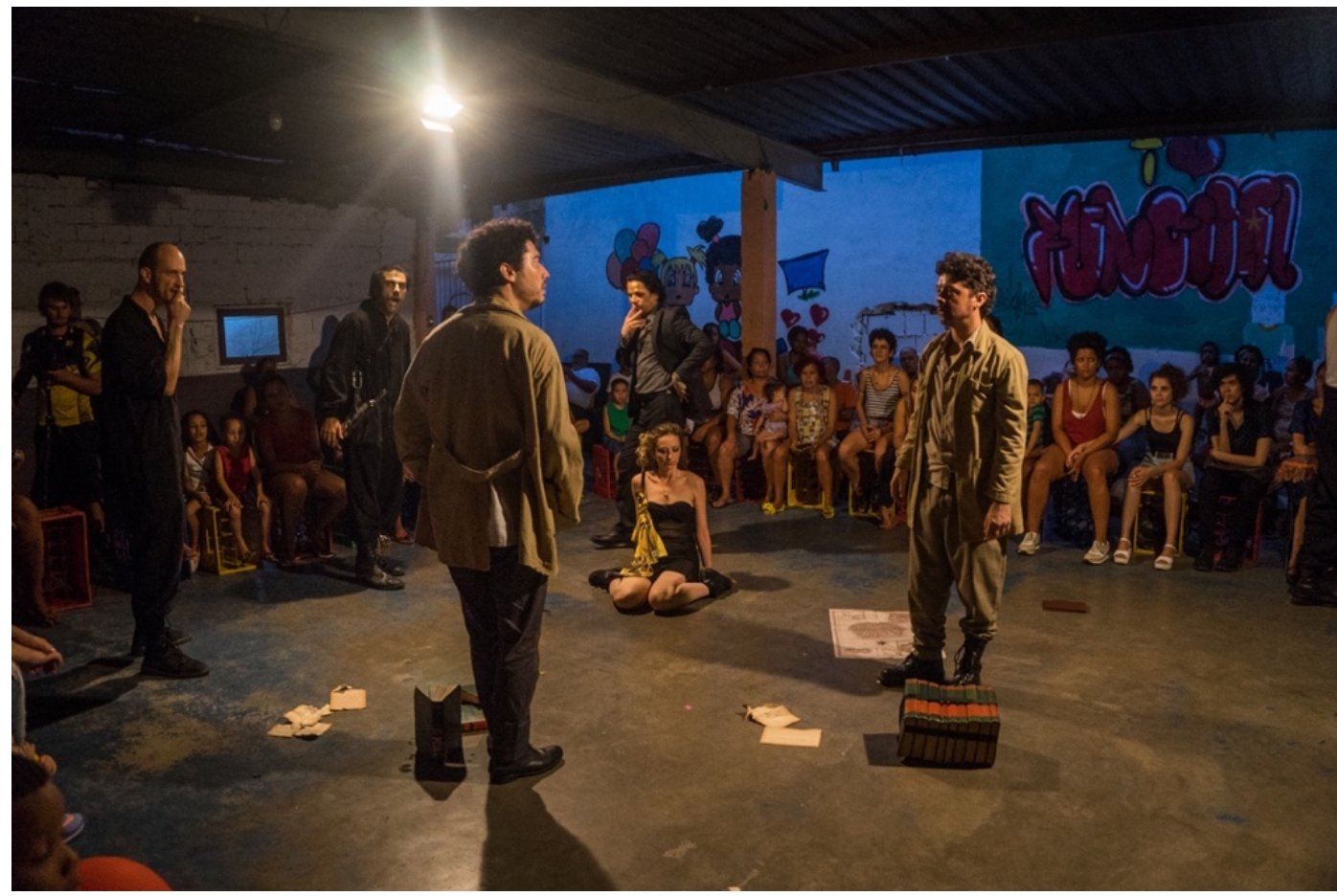

Fonte: Beto Eiras. Acervo mundana companhia

Figura 2: Ocupação \#6 - Terras - Quadro dois - Terreno da comunidade

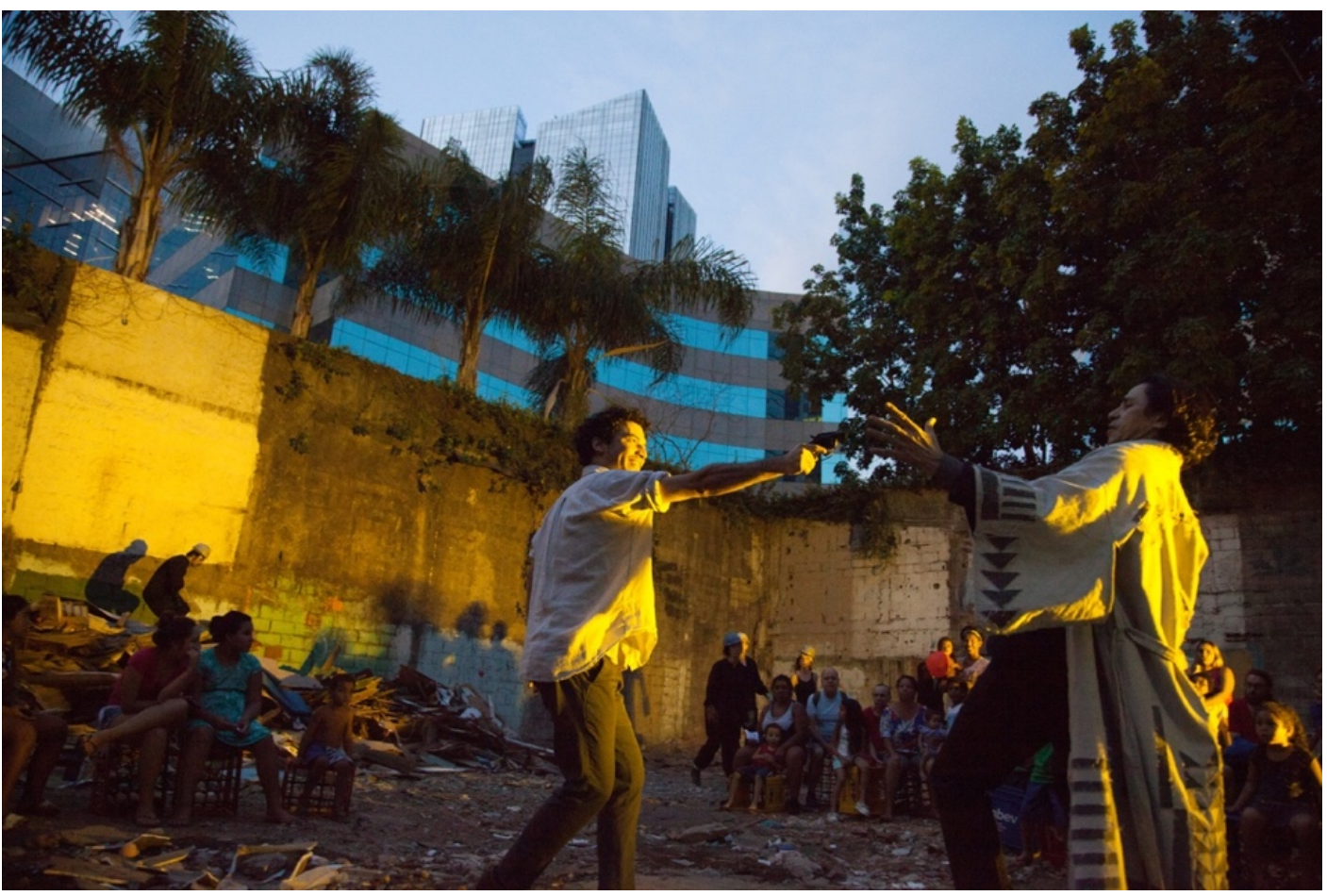

Fonte: Felipe Castellari. Acervo: mundana companhia 
Figura 3: Ocupação \#6 - Terras - Quadro Dez - Terreno da Comunidade

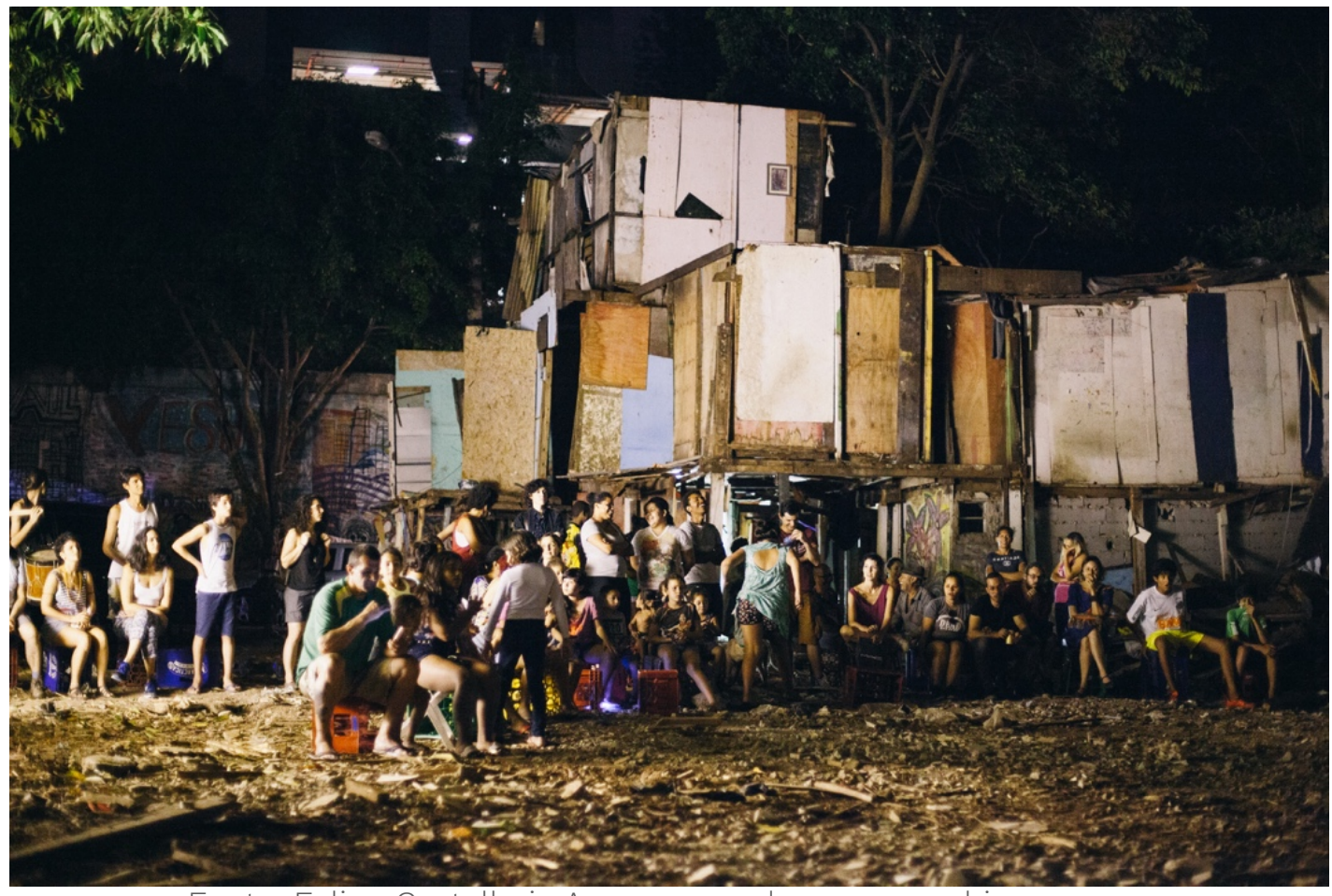

Fonte: Felipe Castellari . Acervo: mundana companhia

Figura 4: Ocupação \#6 - Terras - Quadro Onze- Terreno da Comunidade

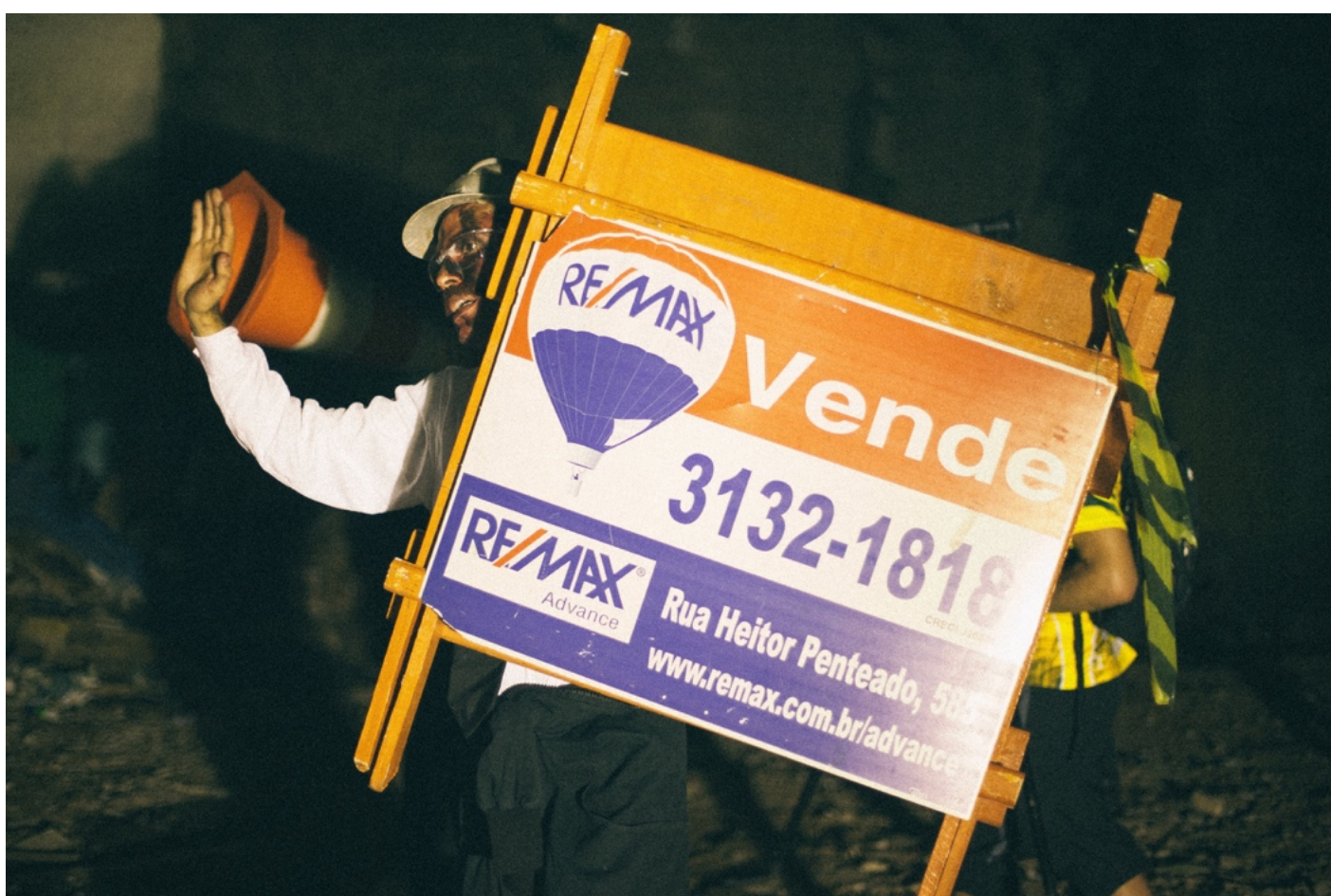

Fonte: Felipe Castellari . Acervo: mundana companhia 


\section{Considerações Finais}

Ao longo destes escritos, procuramos evidenciar, não apenas ao evocarmos a Ocupação \#6 - Terras, mas ao expor o trabalho realizado pela mundana companhia ao longo do projeto Na Selva das Cidades - Em Obras, a potência do espaço da cena como um elemento estruturante e ativo da encenação, e, nesse caso específico, na cidade como espécie de espinha dorsal da peça e de todo o projeto. Nesse sentido, como um duplo movimento, inverte-se esta afirmativa e aponta-se a potência que as práticas teatrais podem adquirir a partir da porosidade ao se deixar organizar a partir de determinada realidade espacial - e também social, já que, como afirmou Lefebvre, uma realidade espacial é também uma realidade social. A partir dessa constatação, a singularidade do trabalho do grupo nos convoca a refletir a respeito de algumas questões.

Primeiro sobre a multiplicidade de leituras que a dramaturgia pôde adquirir a partir das incursões pela cidade, mas também as múltiplas e distintas formas de encenação que o texto foi ganhando em cada um dos locais por onde passou. No caso da Ocupação \#6 - Terras, o texto foi realizado integralmente com as cenas em sequências e o que se desenhava em um primeiro plano era a luta pela terra. Mas por exemplo, na Ocupação\#11 - Morte, realizada no Cemitério da Lapa inverteu-se a ordem dos quadros de modo que a peça começava com o velório de Shlink. Nesse caso, embora o conflito central da disputa entre os homens tenha permanecido, outros aspectos, ligados sobretudo à existência e à morte tomaram contornos mais aparentes. Afinal, Shlink e Garga entram em uma batalha fatal onde apenas um deles sai vivo.

No caso da Ocupação \#10 - Love Story, ocorrida em uma boate do centro da cidade, que tem como frequentadoras cativas profissionais do sexo - a boate não é o espaço de trabalho delas -, o espetáculo adquiriu também outros contornos. Houve, por exemplo, uma alteração considerável no texto, aumentando a participação das figuras femininas, utilizadas como isca e moeda de troca na luta dos dois personagens principais. Nesse caso, buscou-se, através das trajetórias 
das mulheres, uma forma de leitura sobre os conflitos da peça e suas razões, os golpes e suas reverberações. Ou seja, é importante considerar as dimensões subjetivas que perpassam a escolha dos lugares e as condições específicas evocadas por ele. A escolha de um espaço no qual a imagem que se constrói é a de objetificação do feminino, do corpo exposto e disposto como mercadoria, a companhia traz à cena essa dimensão social, cultural e política que perpassa a vida das mulheres. E, dentro de limites dados pela dramaturgia - a decadência humana na selva das cidades -, o grupo subverteu aspectos do texto ainda bastante machistas, assim como aumentou a importância das personagens femininas dentro do jogo. E, embora esse não seja o tema da peça, em muitos momentos acabou se convertendo nele, dadas as condições engendradas pelo local e pela forma como a companhia se abriu para ouvir suas vozes.

Pensando sobre alterações formais que reverberam também nas possíveis leituras da peça, aponta-se, ainda, o caso da Ocupação\#14 - Catch, na qual o grupo transformou a disputa entre Shilink e Garga literalmente em uma luta física, armando um ringue de boxe em plena "cracolândia", suprimindo as falas dos atores e inserindo um narrador/juiz que trazia os principais eixos do enredo da peça - ali, a condição em que se encontram os usuários de drogas e as pessoas em situação de vulnerabilidade social que vagam pelas ruas Região da Luz encontrou uma reverberação potente no jogo corporal e físico dos atores. Já na Ocupação\#15 - Caos, no Teatro Oficina, foram realizados integralmente apenas os quadros um, dois, três e dez - do quadro quatro ao nove foi realizado o que a companhia denominou como interlúdio caótico, misturando trechos das referidas cenas. Inevitável não apontar que a ocupação ocorrida no Oficina, por exemplo, ergue em cena, para além do conflito central, uma relação com a subjetividade e com o imaginário coletivo presente no campo teatral brasileiro, afinal a montagem do mesmo texto dirigida por José Celso Martinez em 1969 é um marco do teatro brasileiro e foi, desde o início do projeto, uma referência explícita no trabalho da mundana. Ou seja, o que é nítido a partir desse trabalho do grupo é a força que o espaço pode exercer dentro de uma obra teatral e que a cada uma dessas ocupações novas camadas das relações do texto com o espaço urbano iam se 
abrindo.

No caso específico da Ocupação \#6 - Terras, o espetáculo se estruturou sobretudo pela batalha enfrentada pela favela e seus moradores contra a coadunação perversa entre o capital privado e o estado, que, há décadas tentam remover a comunidade e seus moradores da área tida como nobre. A encenação se organizou também a partir dos múltiplos elementos que pulsam no cotidiano da comunidade e que a todo momento adentravam a cena. Nesse sentido, a prática teatral empreendida pela mundana permitiu que a dinâmica e os fluxos da favela, para além da luta entre Shlink e Garga, fosse o grande condutor da ocupação. Da materialidade do espaço às pequenas e muitas interferências da vida na Coliseu, o território invadiu a cena e foi invadido por ela.

Assim, a dimensão para qual aponta o trabalho da companhia diz justamente da possibilidade de entender o espaço cênico como espaço social, e em razão disso, por meio dessa polifônica montagem, poder evidenciar a dialética sobre a qual se funda a produção da cidade capitalista nos dias que correm. No caso da Coliseu, por exemplo, o espetáculo revela que o espaço urbano é regido sobre a lógica do dinheiro e do lucro e se organiza cada vez mais a partir dos interesses espúrios do capital. Nesse caso, as Operações Urbanas - tal como a que vigora na região da Coliseu - configuram uma ferramenta extremamente eficaz na reprodução das desigualdades e dos abismos sociais do país. A contradição entre a Coliseu e seu entorno, portanto, revela de forma explícita a afirmação de Lefebvre de que "a luta de classes, hoje mais que nunca, se lê no espaço." (Lefebvre, 1991, p.52).

Entretanto, na contramão dessa lógica, em meio às estratégias capitalistas que ditam o funcionamento da cidade e da vida urbana, existem as táticas subversivas de seus usuários ${ }^{31}$ que agem em oposição a essa dinâmica. As favelas,

31 Para o pensador Michel de Certeau, em A invenção do cotidiano (1980 [1994]), as relações sociais determinam os indivíduos, e não o contrário. Nesse sentido, o autor reflete acerca dos modos de operação dos usuários sobre os produtos culturais - e, associando a leitura de Lefebvre à de Certeau, entendemos o espaço urbano como um desses produtos. Certeau afirma que embora exista todo um sistema de controle e vigilância que nos é imposto, as práticas cotidianas emergem como possibilidades de escapar a esse controle. A partir desta ótica de que existem procedimentos quase ocultos nas práticas microbianas que revelam a oposição ao sistema dominante, Certeau sustenta que existem duas possibilidades de se pensar essa produção - entendida aqui como uma produção espacial. Por meio das estratégias, que 
pela forma como se estruturam, pela prática construtiva que engendram denominada autoconstrução -, pelos meios através dos quais são produzidas, pelos materiais que empregam, pelo envolvimento dos moradores na produção da habitação e do próprio espaço urbano, são lidas como ações táticas dos usuários astuciosos da urbe. A cidade informal como uma bricolagem realizada a partir da ordem preestabelecida, que, por meio de ações não mercantilizadas, opera golpes no sistema e na cidade capitalista. Além disso, outras táticas podem ser apontadas, como a existência da sede como lugar de organização política dos moradores e como espaço para a proposição de atividades culturais e educativas, os eventos festivos promovidos pela comunidade, os pequenos comércios e serviços da e para a comunidade e os pequenos gestos cotidianos de colaboração, cooperação e solidariedade e partilha entre os moradores. É nesse sentido que a favela reivindica o valor de uso do espaço urbano. Ou seja, embora existam enormes pressões para deixar o local, a consciência política de seus moradores, a resistência e organização coletiva fizeram e fazem com que, a duras penas, a comunidade permaneça em seu território até hoje - embora a sua remoção pareça estar cada dia mais próxima. Onde existe a repressão (e a opressão sempre existirá), também haverá a subversão e a resistência.

Cabe apontar ainda que ao ocupar o espaço da comunidade da forma como o fez - se estruturando a partir daquela espacialidade -, a mundana inevitavelmente incorpora na cena as táticas existentes - seja no âmbito material ou subjetivo. Além disso, a própria prática cênica empreendida pelo grupo pode também ser lida como um tática, uma vez que ela reorganiza esses textos urbanos, sobrepõe e contrapõe camadas históricas, políticas, sociais, culturais e simbólicas. É por essa perspectiva que ela também se inscreve como uma prática de resistência, que (re)toma o espaço da cidade, ainda que por um determinado

poderiam ser lidas como vetores que atuam de cima para baixo. Em oposição às estratégias, as táticas seriam melhor representadas por vetores horizontais, elas se apropriam de uma realidade e a transformam por dentro e de baixo para cima. O que distingue as estratégias das táticas seriam "os tipos de operações nesses espaços que as estratégias são capazes de produzir, mapear e impor, ao passo que as táticas só podem utilizá-los, manipular e alterar" (Certeau, [1980], p.92). Ou seja, mesmo dentro de um sistema que impõe certas determinações - e esse sistema se ergue a partir do modo de produção capitalista -, surgem possibilidades de subvertê-lo, e a diferença entre as duas reside no fato da estratégia determinar e a tática subverter. Dentro dos traços impostos, da sintaxe pré-estabelecida surgem as trilhas indeterminadas. 
tempo, como o lugar da festa. E ao atuar de tal forma, o teatro soma suas ações e amplifica os múltiplos coros que lutam em diferentes lugares e de distintas formas pelo direito à cidade ${ }^{32}$.

Por fim, um último apontamento a respeito da potência de significações do trabalho desenvolvido pelo grupo diz de um olhar singular e atual acerca das proposições estéticas e políticas do pensamento e teatro de Bertolt Brecht. Na Selva das Cidades - Em Obras permite que a cidade, ou seja, a vida real, funcione como um elemento que atua de diferentes maneiras sobre o texto, provocando em cada um dos espaços por onde passou possibilidades de leitura sobre a condição humana e urbana nos tempos de hoje. A companhia coloca o teatro brechtiano do pensamento crítico, da luta de classes, de revelação das relações de poder e dominação engendradas pelo capital, frente à atual dinâmica urbana de São Paulo e efetivamente desvela questões e contradições nas quais estamos imersos e que somos constantemente convocados a não assimilar. Afinal, como afirma Brecht em relação ao seu teatro épico - e que nos parece ir de encontro às proposições estética e políticas da mundana companhia -, "essa cortina que nos oculta isto e aquilo, é preciso arrancá-la." (Brecht, 1978, p.112).

\section{Referências}

ARAÚJO, Antônio. A Gênese da Vertigem, São Paulo: Perspectiva, 2011.

BRECHT, Bertolt. Na Selva das Cidades [1923]. In: Imersão Selva. São Paulo. 2016.

CARREIRA, André Luiz Antunes Netto. Ambiente, fluxo e dramaturgias da cidade: materiais do Teatro de Invasão. In: O Percevejo Online. Rio de Janeiro, v. 1, n. 1, 2009.

32 A ideia de um direito à cidade nos é apresentada por Lefebvre em 1968 no livro O Direito à Cidade, e retomada por David Harvey, em Cidades Rebeldes ([2012] 2013), para pensar os movimentos de reivindicação do espaço da cidade como um bem comum - na concepção de Harvey - e na cidade como obra - na concepção lefebvriana. Lefebvre aponta que o direito à cidade não significa simplesmente retomar uma tradição urbana perdida, mas um direito à vida urbana transformada, no qual o valor de uso seja prioritário. Harvey aponta ainda que "A questão de que tipo de cidade queremos não pode ser divorciada do tipo de laços sociais, relação com a natureza, estilos de vida, tecnologias e valores estéticos que desejamos. O direito à cidade está muito longe da liberdade individual de acesso a recursos urbanos: é o direito de mudar a nós mesmos pela mudança da cidade.". (Harvey, 2012, p.81). 
CARLOS, ANA FANI. O direito à cidade e a construção da metageografia. In: Revista Científica Cidades / Grupo de Estudos Urbanos - Vol. 1, n. 1, 2004 - Presidente Prudente: Grupo de Estudos Urbanos, 2005 - v.2, n. 4, p. 221-248.

CERTEAU, Michel de. A invenção do cotidiano: artes de fazer. Petrópolis, RJ: Vozes, $1994[1980$.

LEFEBVRE, Henri. The Production of Space. Trad. D. Nicholson-Smith Oxford: Basil Blackwell, 1991[1974].

LEFEBVRE, Henri. O Direito à Cidade. Trad. Rubens Eduardo Frias. São Paulo: Centauro, 2001 [1968].

FORJAZ, Cibele. Das imersões ao conceito do espetáculo Na Selva das Cidades em obras. In: Imersão Selva. São Paulo, 2016.

FORJAZ, Cibele. Entrevista realizada pela autora em janeiro de 2019.

HARVEY, David. O direito à cidade. In: Revista Lutas Sociais, São Paulo, n.29, p.7389, jul./dez. 2012.

IRWIN, Kathleen. Layering Space - speaking from place. In. Space and Post Modern Stage. Org. Eva Šormová, Irene Eynat-Confino. Praga: MUStudios, 2008.

PAVIS, Patrice. Dicionário de Teatro. São Paulo: Perspectiva, 2011.

PEIXOTO, Fernando. Brecht: Vida e Obra. Rio de Janeiro: Paz e Terra, 1974.

Recebido em: 16/06/2020

Aprovado em: 27/07/2020

Universidade do Estado de Santa Catarina - UDESC

Programa de Pós-Graduação em Teatro - PPGT

Centro de Arte - CEART

Urdimento - Revista de Estudos em Artes Cênicas

Urdimento.ceart@udesc.br 